\title{
Correction to: Laser Additive Manufacturing of Magnetic Materials
}

\author{
C.V. MIKLER ${ }^{1}$ V. CHAUDHARY,${ }^{2}$ T. BORKAR ${ }^{3}$ V. SONI,${ }^{1}$ D. JAEGER,${ }^{4}$ \\ X. CHEN,${ }^{2}$ R. CONTIERI,${ }^{5}$ R.V. RAMANUJAN,${ }^{2}$ and R. BANERJEE ${ }^{1,6}$ \\ 1.-Department of Materials Science and Engineering, University of North Texas, Denton, \\ TX 76201, USA. 2.-School of Materials Science and Engineering, Nanyang Technological \\ University, Singapore 639798, Singapore. 3.-Department of Mechanical Engineering, Cleve- \\ land State University, Cleveland, OH 44115, USA. 4.-Center for Advanced Research and \\ Technology, University of North Texas, Denton, TX 76201, USA. 5.-FCA/UNICAMP, Limeira, \\ SP CEP 13484-350, Brazil. 6.-e-mail: Rajarshi.Banerjee@unt.edu
}

\section{Correction to: JOM, Vol. 69, No. 3, 2017, DOI: $10.1007 / \mathbf{s 1 1 8 3 7 - 0 1 7 - 2 2 5 7 - 2}$}

In the published version of this paper, there is an error in the indexing of the fcc diffraction pattern in Fig. 5c. The corrected figure is shown below (Fig. 5). 

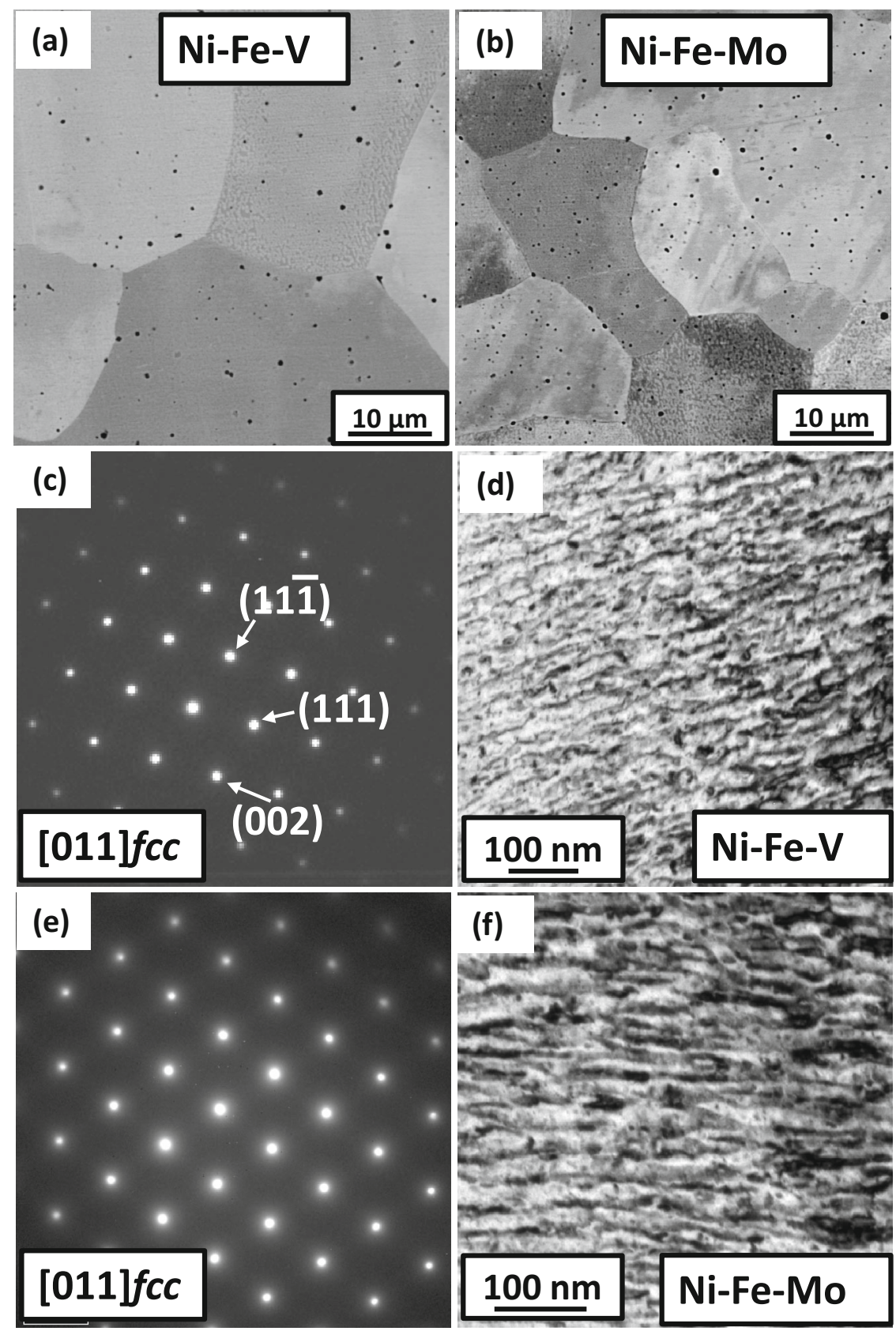

Fig. 5. SEM images of LENS ${ }^{T M}$-deposited (a) Ni-Fe-V and (b) Ni-Fe-Mo alloy as well as selected area diffraction patterns and bright-field TEM images of $\mathrm{Ni}-\mathrm{Fe}-\mathrm{V}(\mathrm{c}, \mathrm{d})$ and $\mathrm{Ni}-\mathrm{Fe}-\mathrm{Mo}(\mathrm{e}, \mathrm{f})$ alloys, respectively 